\title{
Frontal Bone Remodeling for Gender Reassignment of the Male Forehead: A Gender-Reassignment Surgery
}

\author{
Johannes Franz Hoenig
}

Received: 4 January 2011/Accepted: 28 March 2011/Published online: 15 May 2011

(C) The Author(s) 2011. This article is published with open access at Springerlink.com

\begin{abstract}
Gender-reassignment therapy, especially for reshaping of the forehead, can be an effective treatment to improve self-esteem. Contouring of the cranial vault, especially of the forehead, still is a rarely performed surgical procedure for gender reassignment. In addition to surgical bone remodeling, several materials have been used for remodeling and refinement of the frontal bone. But due to shortcomings of autogenous bone material and the disadvantages of polyethylene or methylmethacrylate, hydroxyapatite cement (HAC) composed of tetracalcium phosphate and dicalcium phosphate seems to be an alternative. This study aimed to analyze the clinical outcome after frontal bone remodeling with HAC for gender male-to-female reassignment. The 21 patients in the study were treated for gender reassignment of the male frontal bone using HAC. The average age of these patients was 33.4 years (range, 21-42 years). The average volume of HAC used per patient was $3.83 \mathrm{~g}$. The authors' clinical series demonstrated a satisfactory result. The surgery was easy to perform, and HAC was easy to apply and shape to suit individual needs. Overall satisfaction was very high. Therefore, HAC is a welcome alternative to the traditional use of autogenous bone graft for correction of cranial vault irregularities.
\end{abstract}

Keywords BoneSource - Forehead feminization · Frontal bone $\cdot$ Gender reassignment

\footnotetext{
J. F. Hoenig ( $\square)$

Department of Plastic and Aesthetic Surgery, University

Hospital and Medical School of Goettingen,

Robert-Koch-Street 40, 37075 Goettingen, Germany

e-mail: info@professor-hoenig.de

J. F. Hoenig

Paracelsus Clinic Hannover, Hannover, Germany
}

\section{Introduction}

Gender identity disorder is an uncommon disease with a prevalence of 1 in 50,000 [1]. But the demand for genderreassignment therapy, especially for reshaping of the forehead, is on the rise. Although it can be an effective treatment to improve self esteem [2-5], contouring of the cranial vault, especially the frontal bone, still is a rarely performed surgical procedure for gender reassignment. Roberts and Bruce [6] suggested that the "overall shape of the head" is significant when specific features are not highlighted or masked, supporting the findings of Sadr et al. [7]. This might be especially important for patients with gender identity disorder, whose external appearance is in conflict with their internal gender identity $[8,9]$.

Females are known to have very little if any brow fullness $[10,11]$. They have a continuous curvature of the forehead in both the axial and sagittal planes. In contrast, males have an area of fullness in the mid forehead, slightly above the brows and extending upward $2-3 \mathrm{~cm}$. Depending on the masculine expression for gender reassignment of the forehead, different cranioplasty techniques have been used for feminization of the forehead in the past [9] including the burring and the osteoplastic flap setback methods. Habal [12] described feminizing cranioplasty using a burring technique in which the forehead was contoured into the diploic space using only osteotomes and a tapping technique [28].

Ousterhout [13-15] included burring, bony flap setback, and methylmethacrylate to contour the forehead. But knowing from reconstructive surgery of the cranial vault that surgical bone reshaping of the forehead without augmentation often is not sufficient, several alloplastic materials such as high-density polyethylene or methylmethacrylate have been widely used for augmentation and remodeling of the 
frontal bone [15-20], thus avoiding the use of autogenous bone.

Although widely used, methylmethacrylate has some disadvantages. It not only forms a capsule in the adjacent areas but also is vulnerable to infections [19]. To overcome this shortcoming, hydroxyapatite cement (HAC) seems to be an alternative [21-33]. An alloplastic material, HAC is composed of tetracalcium phosphate and dicalcium phosphate anhydrous that transforms into a paste-like substance when these compounds are placed in a liquid environment [34-37]. Animal studies [21-23] have shown that HAC has a high osteoconductive capacity, so it is an excellent alternative for craniofacial contour refining [19, 21-23, 31, 33].

This study aimed to analyze the clinical outcome for gender reassignment remodeling of the forehead from male to female using HAC.

\section{Patients and Methods}

\section{Patients}

The patients treated were undergoing gender-reassignment surgery of the frontal cranial vault from male to female. These 21 patients, who underwent frontal cranial vault plasty, were reshaped by a burring down of the supraorbital ridge and the frontal bossing and a recontouring of the forehead through augmention with HAC (BoneSource; Stryker Leibinger GmbH, D-79111 Freiburg, Germany) during a 36 month period. The average age of these patients was 33.4 years (range, 21-42 years). All the patients were men. They were treated for feminization of the frontal bone, which included removing the boosing, burring down the supraorbital ridge with a drill (Fig. 1a-c), and contouring the upper and upper lateral orbital rim in conjunction with remodeling the forehead using HAC
(Figs. 2, 3, 4). The average volume of HAC per patient was $8.83 \mathrm{~g}$, and the average reduction of the bossing was $3 \mathrm{~mm}$.

An independent evaluation of the results 1 year after the operation on a 4-point scale (from excellent to poor) was performed. After clinical examination, photographs were taken 6 and 12 months postoperatively and reviewed independently by two residents, who recorded the measurements. The results were semi-quantified, and a mean score was calculated.

\section{Technique}

Our animal investigations [21-23] showed that intraoperative time depends on solubility of the powders, regulated primarily by the liquid solvent, which influences the osseointegration by decreasing the microporous structures and porosity rate. With a mean pore diameter of 5-10 nm of HAC, sterile water was used as a solvent in our study. $\mathrm{HAC}$ has a set time of $15 \mathrm{~min}$, enabling the surgeon to mold and reshape the HAC with the cranial vault form and also making possible a homogeneous osteoconversion over a shorter time.

A coronal approach was used, reflecting the frontal orbital flap, to expose the cranial vault. After burring down of the supraorbital ridge and the frontal bossing, HAC was used in infection-free, good-quality surroundings and underlying bone beds with adequate, well-vascularized overlying tissue. After the powder and liquid compositions had been mixed intraoperatively, the paste was contoured onto the forehead and subsequently converted in vivo by direct crystallization without heat formation to hydroxyapatite (Fig. 4).

Once applied, the putty was molded into the desired aesthetic refinement of the frontal bone contour (Figs. 3b, $4 b)$. Final contouring was followed by scraping with elevators or Tessier spatulas and molding with wet powderfree glove fingers. The solidification process was completed
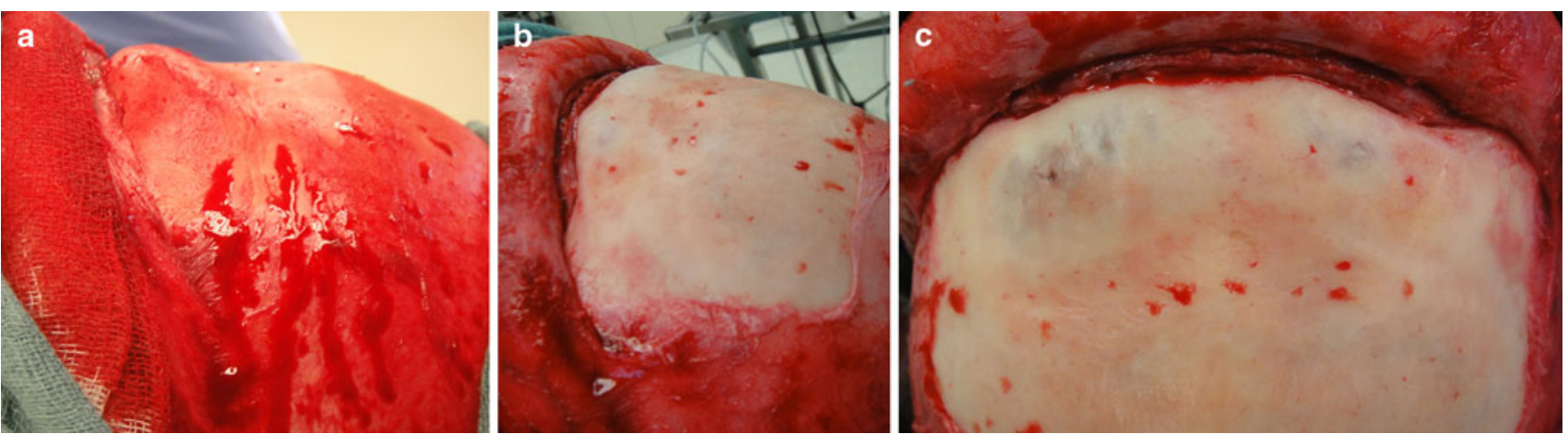

Fig. 1 Intraoperative views of the bony forehead after subperiosteal reflection of the forehead soft tissue using a coronal incision. a Lateral view. Note the severe boosing of the orbital rim with a supraorbital concavity of the forehead. The boosing was reduced by burring down into the diploe until the frontal sinus was shining through before augmentation of the supraorbiatal cavitation. b Lateral view with tremendous thinning of the anterior wall frontal sinus. c Cranial eccentric view 


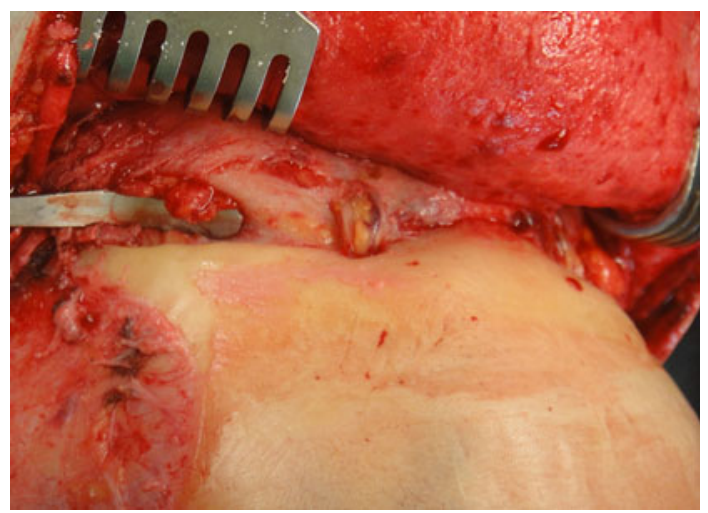

Fig. 2 Intraoperative oblique view of the bony forehead after subperiosteal reflection of the soft tissue. The neurovascular bundle is preserved, and the lateral orbital rim was trimmed to reduce the bony hooding

within 10-15 $\mathrm{min}$ for the formation of hydroxyapatite during the next 6-8 h. Drainage was left in place for $24 \mathrm{~h}$.

\section{Results}

The median observation time was 18 months. Immediate healing was achieved without complications, adverse reactions, or side effects. All the patients healed uneventfully. No swelling or seromatous fluid collection necessitated a second procedure or prolonged drainage. No failure of the material to set up and no postoperative "wash out" of the reconstruction area was observed.

Satisfactory remodeling of the frontal cranial vault occurred in all treated patients without any postoperative problems. The aesthetic results were considered good to excellent in 15 cases and satisfactory in two cases. The contour results were stable in long-term follow-up evaluations. Touch, shape, and stability were achieved immediately after surgery. Figures 5, 6 and 7 illustrate the indications, treatments, and results.

\section{Discussion}

In 2011, Spiegel [8] investigated the facial determination of "female gender and feminization forehead cranioplasty," showing that the prominence of the forehead at the glabella region and the position and shape of the eyebrows are the most significant for determining female gender. $\mathrm{He}$ pointed out that the upper third of the face is the most significant part of the face for determining female gender in both the frontal and profile views of the face $[8,9]$. His
Fig. 3 Intraoperative lateral views of the bony forehead after subperiosteal reflection of the soft tissue and bony remodeling with burring down the boosing over the orbital rim of the forehead. a Note the flat frontal forehead without any convexity. b To reassign the forehead from male to female after bony reshaping of the cranial vault, hydroyapatite cement (HAC) was applied for augmentation and recontouring of the forehead

Fig. 4 Intraoperative bony forehead cranial views. a Before and $\mathbf{b}$ after reshaping of the forehead. After drilling down the boosing, the forehead was augmented using hydroyapatite cement (HAC) to recontour the bony forehead. Note the achieved spherical curvature of the frontal bone in the sagittal and horizontal planes by application of HAC to the forehead
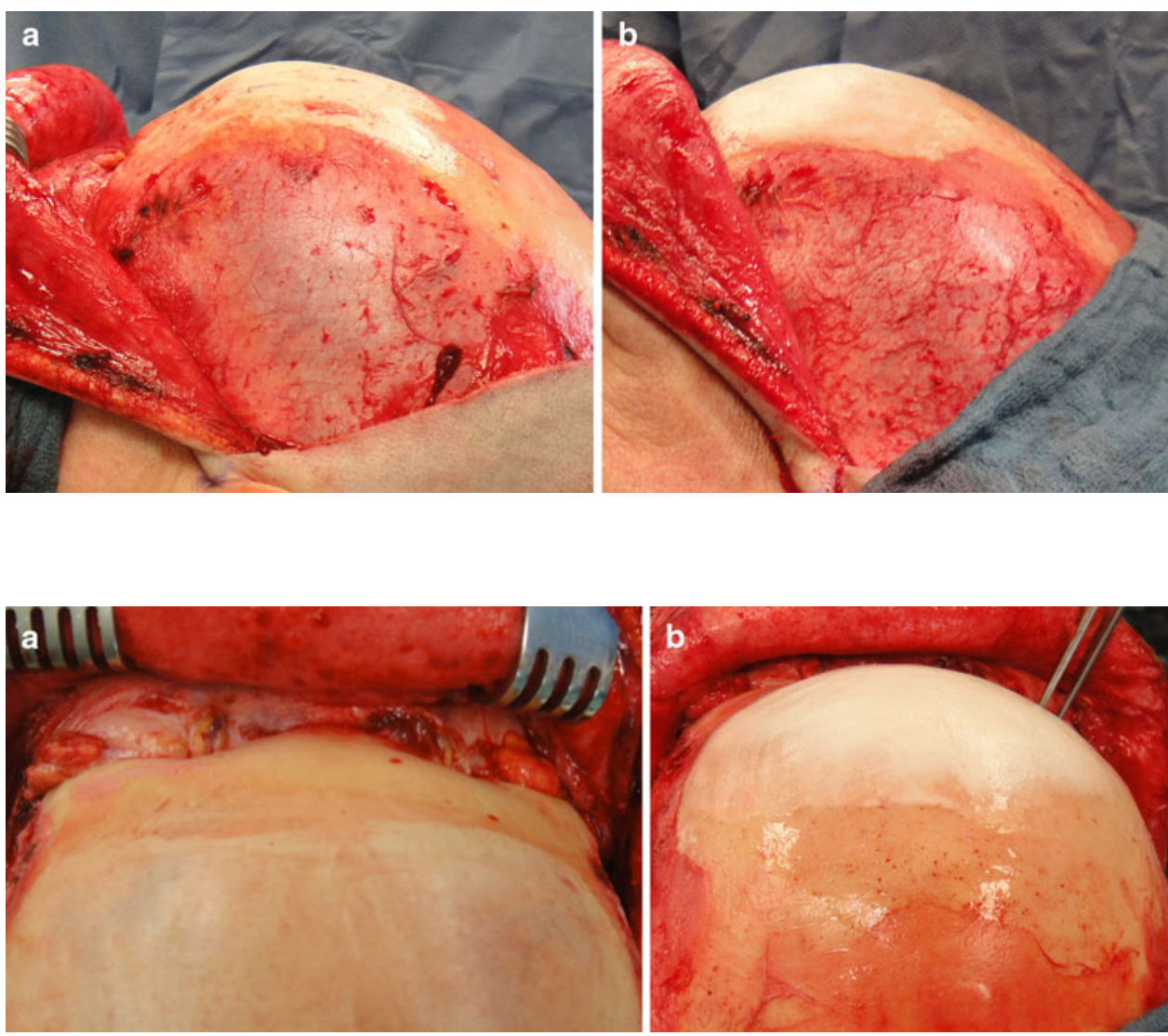

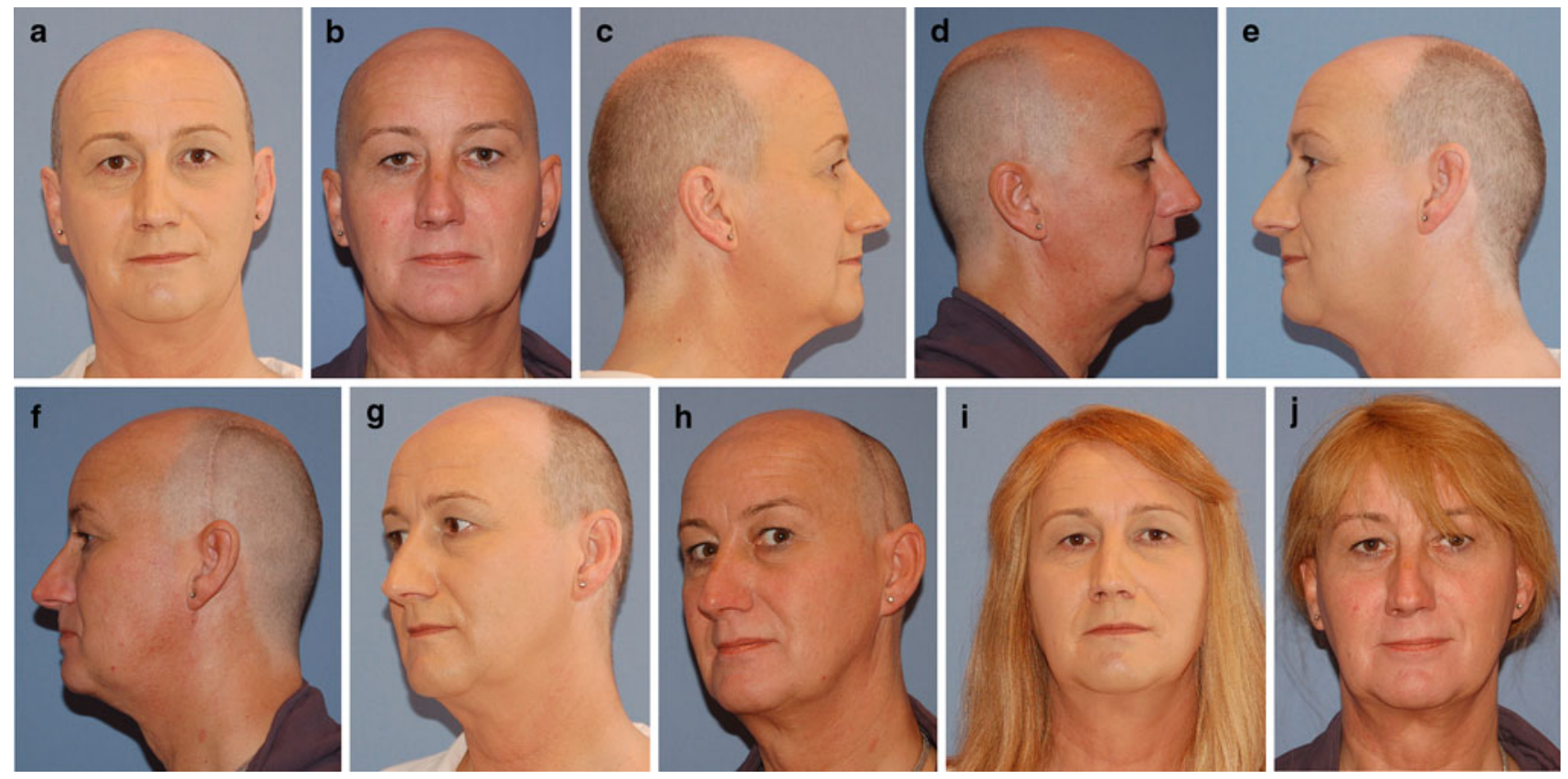

Fig. 5 Views $(\mathbf{a}, \mathbf{c}, \mathbf{e}, \mathbf{g}, \mathbf{i})$ before and $(\mathbf{b}, \mathbf{d}, \mathbf{f}, \mathbf{h}, \mathbf{j}) 1$ year after surgery performed for a 42-year-old person to accomplish gender reassignment of the forehead. (a, c, g, i) The forehead is flat. (d, f) After drilling down the lateral hooding, a new forehead

curvature was established by three-dimensional forehead augmentation using hydroyapatite cement (HAC). Note the far distal prehairline coronal forehead incision to avoid a scar on the man's bald forehead
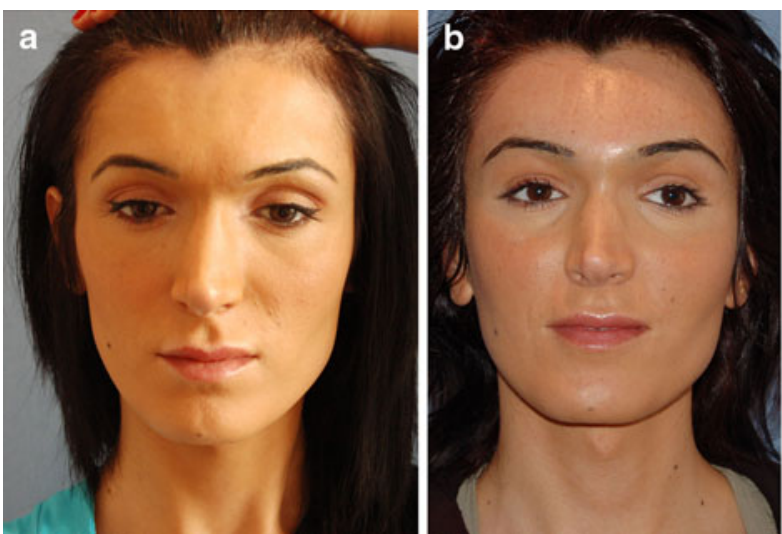

Fig. 6 Views $(\mathbf{a}, \mathbf{c}, \mathbf{e})$ before and $(\mathbf{b}, \mathbf{e}, \mathbf{d}) 15$ months after surgery performed for a 22-year-old male-to-female person. The flat masculine forehead has been surgically reshaped by drilling down the

study showed that the frontal view of the forehead modification was selected as most feminizing more often than the profile view [8].

In agreement with Spiegel's [8] investigation, our study clearly supported the strong significance of forehead modification in permitting transgendered patients to be identified as women. Therefore, remodeling of the forehead for gender reassignment is an extensively satisfying procedure if several characteristic gender differences of the forehead are appreciated when the bony forehead is modified [6-9]. The male bossing all the way across the orbital
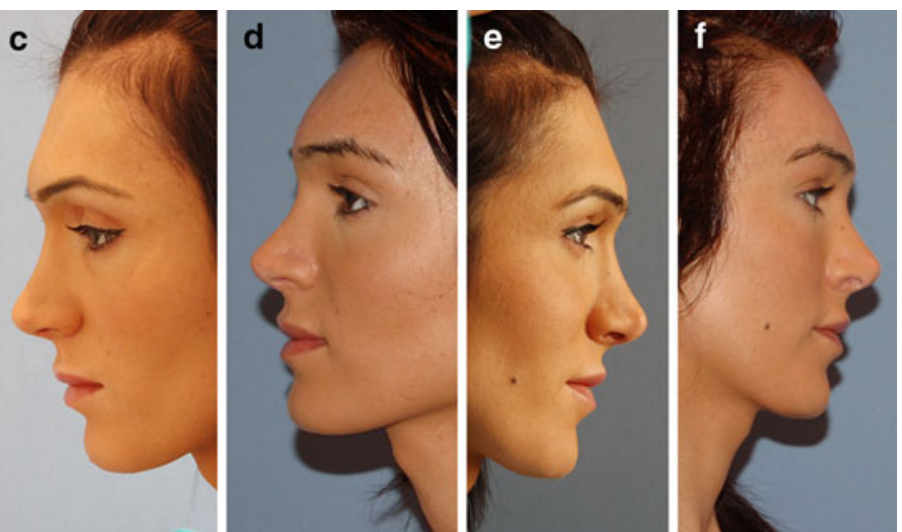

boosing and applying hydroyapatite cement (HAC) into a pleasing female forehead curvature. At this writing, secondary rhinoplasty still is pending since the follow-up evaluation

rims, with a depression between the brows, can cause marked shadowing of the eyelids and eyes and is a factor in hooding of the lateral superior orbital rim. Thus, for maleto-female reassignment, bossing across the orbital rims and hooding of the lateral orbit must be reduced, whereas the concavity on the forehead above the area of the residual bossing must be filled $[8,13]$. This procedure eliminates the masculine characteristic and gives a continuous female curvature of the forehead.

Despite the huge amount of literature devoted to alloplastic reconstruction of the cranial vault, only limited 
Fig. 7 (a, c, e) A 24-year-old patient with severe bossing all the way across the orbital rims. Note the depression between the brows and the supraorbital concavity of the forehead. Contouring of the forehead was performed by burring down into the diploe until the frontal sinus was shining through and augmenting the supraorbiatal depression using hydroyapatite cement (HAC).

$(\mathbf{b}, \mathbf{d}, \mathbf{f})$ Postoperative view 14 months after surgery. (b, f) The contouring of the forehead mainly reduces the masculine expression and gives a more pleasing forehead with little if any brow fullness
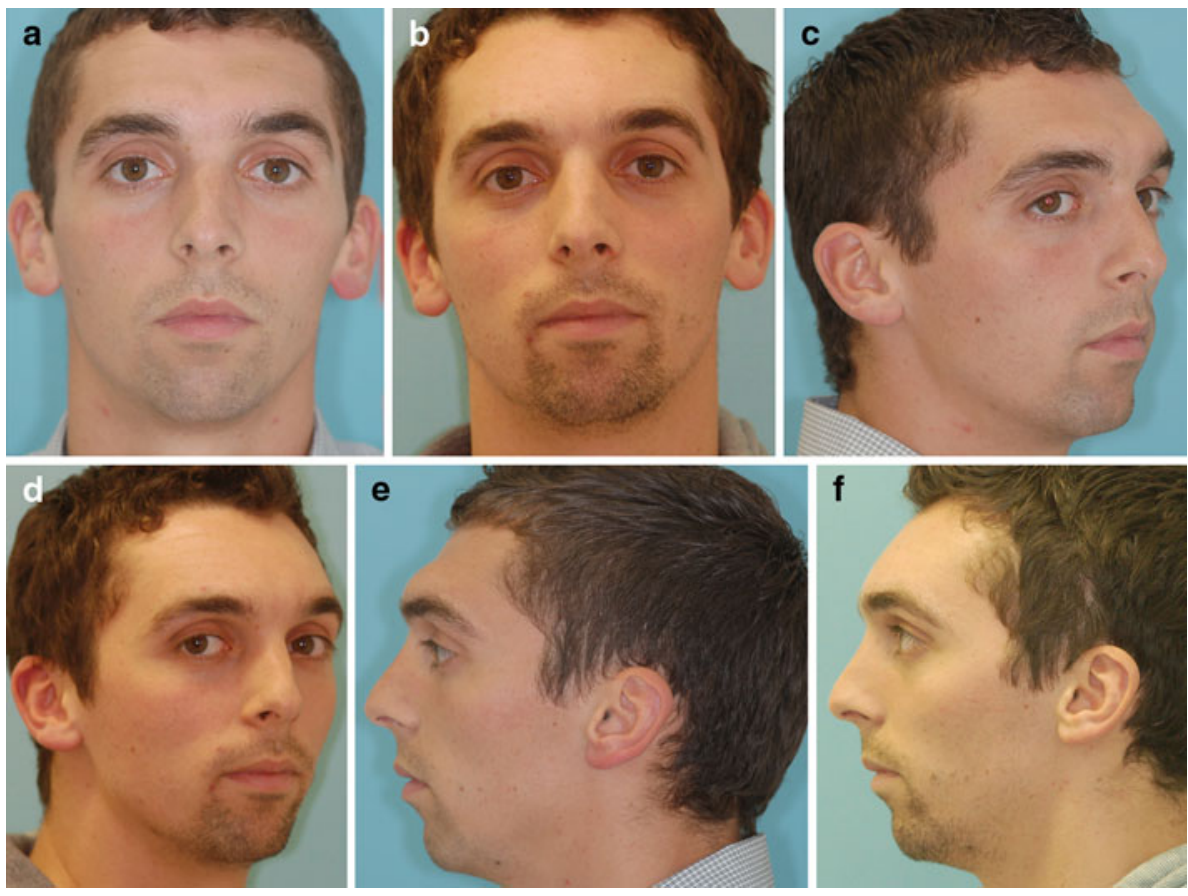

experience with feminizing surgery for the craniofacial area exists [12, 14, 19, 21]. For instance, Becking et al. [38] reported on transsexual patients who underwent "bony facial corrections," but none of these patients had procedures on the upper third of the face. This article reports the largest volume of patients undergoing feminizing cranioplasty and supports the overall safety of the methods.

For augmentation of the cranial vault, hydroxyapatite cement is a welcome alternative to high-density polyethylene or methylmethacrylate as well as the traditional use of autogenous bone, especially for gender reassignment $[19,21,22,24]$. The material maintains its intraoperative position after surgery $[22,23]$. It is biocompatible and has good outcomes [21-23, 26-29, 31, 39, 40].

Our own animal studies on histologic examination of HAC showed fine fibrous septa containing newly formed small vessels [21, 22]. Sparsely distributed focal ossification areas characterized by an ossification matrix with osteocytes embedded in lacunae were seen. These observations support the osseointegration of the implant and showed in the animal study that although limited, there was new bone and vascularized formation within the HAC [22].

The high osteoconductive capacity of HAC makes it an excellent alternative for gender reassignment of the cranial vault [21]. It is incorporated within the surrounding bony structures and permits secondary procedures [19, 22, 23].

Our own experimental studies [21, 22], performed to show the safety and osseointegration capacity of HAC with animal models, confirmed the osseous replacement without any toxic reactions or increases in serum calcium or phosphate levels, as shown by Friedman et al. [25]. As the findings demonstrated, HAC is gradually reabsorbed and replaced by bone. The newly formed bone appeared to be effectively remodeled over time, producing lamellar bone nearly indistinguishable from normal, mature osseous tissue [22]. This osteoconductive property prevents migration of the paste applied on the cranial vault and lowers the postoperative infection because of its vascular ingrowth $[22,23]$. The capacity for osteoinduction was found to be dependent on the rate of the porosity and microstructure, with a mean pore diameter of $8 \mathrm{~nm}$, depending on the amount of the solvent water, which enables the homogeneous osteoconversion. But our histologic examinations on Goettingen minipigs showed that the porosity and microstructure are dependent on the liquid substance. Mixing the HAC powder with sodium monophosphate intraoperatively decreases the microstructure of the resulting hydroxyapatite and limits the amount, tending to decrease the longer the material is exposed to a moist environment [40].

Even if the anterior wall of the frontal sinus needs to be set posteriorly and fixed with plates into a more reduced position for aesthetic reasons, HAC is used for additional contouring. It seals the bony fragments of the anterior frontal sinus wall after meticulous cleaning and checking of the sinus to ensure that the frontal nasal ducts are open and will be replaced by bony tissue over the time [39, 40].

Clinical and experimental studies have shown that HAC is a biocompatible substance that does not cause any chronic, inflammatory, allergenic, or toxic reaction [19, 21, $22,26]$. Therefore, it has a better resistance to bacterial infection, although inflammatory immunologic reactions have been reported by Moreira-Gonzalez et al. [18] and 
others [16]. Moreira-Gonzalez et al. [18] analyzed posttumor patients who had undergone cranioplasty using the various materials currently available. For the group of patients reconstructed with $\mathrm{HAC}$, these authors reported an inflammatory immunologic reaction occurring some months to some years at least after implantation and resulting in erosion of the skin and exposure of the underlying material, requiring its removal. Whether the reported complications are related to subclinical infection, trauma, or the material itself remains unclear.

Since 2002, we have used a bone source for cranial vault reconstruction and recontouring, especially for augmentation of the forehead in nonsyndromic and non-post-tumor patients without seeing any postoperative complications [21] such as inflammatory reactions with swelling or mild redness over an 8 year period, which is in agreement with others $[19,21-24,27-35,39,40]$. Perhaps because no previous trauma or infections took place before frontal bone remodeling gender reassignment of the bony forehead in conjunction with HAC, augmentation has been a safe procedure without any major complications over the past several years in our hands. The operative time for recontouring of the cranial vault usually has been $1-1.5 \mathrm{~h}$.

Since the first description of aesthetic forehead augmentation with methylmethacrylate by Gonzalles-Ulloa and Stevens [20], several materials including titanium, polyethelene, silicone, and rib bones have been used for cranioplasties but are no longer considered. By allowing long-lasting contouring of the noninfected bony forehead for gender reassignment, HAC avoids autogenous material. In contrast to established polymethylmethacrylate (PMMA)-based cements, application of the BoneSource cement enables ossification throughout an augmented volume. In addition, PMMA forms a capsule in the adjacent areas, is vulnerable to infections, and needs fixation [19]. Due to the possibility that the adjacent tissue might be damaged because of the chemical thermogenic reactions that occur during the hardening process, its clinical application has been restricted [19]. Whether the high-density polyethylene forms a capsule in the adjacent tissue or not, this material cannot fuse with the adjacent bone tissue. This eventually increases the incidence of infection and possibility of extrusion.

\section{Conclusion}

This clinical series demonstrated that a satisfactory result can be achieved in one surgical session for patients requesting cranial vault remodeling for gender reassignment using HAC. The HAC (BoneSource R) is gradually be reabsorbed and replaced by bone. It permits osseointegration, which makes it relatively resistant to infection. The substrate is available in amounts (volumes) that are easy to apply and shape to suit individual needs. Overall satisfaction is very high. Therefore, HAC is an alternative to autogenous bone grafts and other alloplastic materials. Forehead plasty for gender reassignment through cranioplasty is safe. It has a significant impact in determining the gender of the patient [41].

\section{Conflicts of interest None.}

Open Access This article is distributed under the terms of the Creative Commons Attribution Noncommercial License which permits any noncommercial use, distribution, and reproduction in any medium, provided the original author(s) and source are credited.

\section{References}

1. Hoenig J, Kenna JC (1974) The prevalence of transsexualism in England and Wales. Br J Psychiatry 124:181-190

2. Hoenig J (1974) The management of transsexualism. Can Psychiatr Assoc J 19:1-6

3. Ross MW, Need JA (1989) Effects of adequacy of gender-reassignment surgery on psychological adjustment: a follow-up of fourteen male-to-female patients. Arch Sex Behav 18:145-153

4. Eldh J, Berg A, Gustafsson M (1997) Long-term follow up after sex reassignment surgery. Scand J Plast Reconstr Surg Hand Surg 31:39-45

5. Dempf R (2010) Eckert AW: contouring the forehead and rhinoplasty in the feminization of the face in male-to-female transsexuals. J Craniomaxillofac Surg 38:416-422

6. Brown E, Perrett DI (1993) What gives a face its gender? Perception 22:829-840

7. Sadr J, Jarudi I, Sinha P (2003) The role of eyebrows in face recognition. Perception 32:285-293

8. Spiegel JF (2011) Facial determinants of female gender and feminizing forehead cranioplasty. Laryngoscope 121:250-260

9. Spiegel JH (2008) Challenges in care of the transgender patient seeking facial feminization surgery. Facial Plast Surg Clin North Am 16:233-238

10. Roberts T, Bruce V (1988) Feature saliency in judging the sex and familiarity of faces. Perception 17:475-481

11. Cellerino A (2003) Psychobiology of facial attractiveness. J Endocrinol Invest 26(Suppl 3):45-48

12. Habal MB (1990) Aesthetics of feminizing the male face by craniofacial contouring of the facial bones. Aesthetic Plast Surg 14:143-150

13. Ousterhout DK (1987) Feminization of the forehead: contour changing to improve female aesthetics. Plast Reconstruct Surg 79:701-711

14. Ousterhout DK (1987) Feminization of the forehead: contour changing to improve female aesthetics. Plast Reconstr Surg 79: 701-713

15. Ousterhout DK, Zlotolow IM (1990) Aesthetic improvement of the forehead utilizing methylmethacrylate onlay implants. Aesthetic Plast Surg 14:281-285

16. Marchac D, Greensmith A (2008) Long-term experience with methylmethacrylate cranioplasty in craniofacial surgery. J Plast Reconstr Aesthet Surg 61:744-752

17. Yaremchuk MJ (2003) Facial skeletal reconstruction using porous polyethylene implants. Plast Reconstr Surg 111:1818-1827

18. Moreira-Gonzalez A, Jackson IT, Miyawaki T et al (2003) Clinical outcome in cranioplasty: critical review in long-term follow-up. J Craniofacial Surg 14:144 
19. Lee DW, Kim JY, Lew DH (2010) Use of rapid hardening hydroxapatite cement for craniofacial surgery. J Craniofac Surg 21:1084-1088

20. Gonzalez-Ulloa M, Stevens E (1964) Implants in the face: a review of our experience in the subcutaneous use of methylmethacrylate. Plast Reconstr Surg 33:532-542

21. Hönig JF, Merten HA, Nitsch A, Verheggen R (2005) Contouring of cranial vault irregularities with hydroxyapatite cement: a clinical and experimental investigation. J Craniofac Surg 16: 457-460

22. Verheggen R, Merten HA, Hoenig JF (2001) Correction of skull defects using hydroxyapatite cement (HAC): evidence derived from animal experiments and clinical experience. Acta Neurochir 143:919-926

23. Rupprecht S, Merten HA, Kessler P (2003) Hydroxyapatite cement (BoneSource) for repair of critical sized calvarian defects an experimental study. J Craniomaxillofac Surg 31:149-153

24. Jackson IT, Yavuzer R (2000) Hydroxyapatite cement: an alternative for craniofacial skeletal contour refinements. Br J Plast Surg 53:24-29

25. Friedman CD, Costantino PD, Takagi S, Chow LC (1998) BoneSource hydroxyapatite cement: a novel biomaterial for craniofacial skeletal tissue engineering and reconstruction. J Biomed Mater Res 43:428-432

26. Shindo ML, Costantino PD, Friedman CD, Chow LC (1993) Facial skeletal augmentation using hydroxyapatite cement. Arch Otolaryngol Head Neck Surg 119:185-190

27. Tuncer S, Yavuzer R, Işik I, Başterzi Y, Latifoĝlu O (2004) The fate of hydroxyapatite cement used for cranial contouring: histological evaluation of a case. J Craniofac Surg 15:243-246

28. Eppley BL, Hollier L, Stal S (2003) Hydroxyapatite cranioplasty: 2. Clinical experience with a new quick-setting material. J Craniofac Surg 14:209-214

29. Eppley BL (2003) Hydroxyapatite cranioplasty: I. Experimental results from a new quick-setting material. J Craniofac Surg $14: 85-88$

30. Epply BL (2003) Alloplastic cranioplasty. Operative Tech Plast Reconstr Surg 9:16-22
31. Stelnicki EJ, Ousterhout DK (1997) Hydroxyapatite paste (BoneSource) used as an onlay implant for supraorbital and malar augmentation. J Craniofac Surg 8:367-372

32. Costantino PD, Chaplin JM, Wolpoe ME, Catalano PJ, Sen C, Bederson JB, Govindaraj S (2000) Applications of fast-setting hydroxyapatite cement: cranioplasty. Otolaryngol Head Neck Surg 123:409-412

33. Sanada Y, Fujinaka T, Yoshimine T, Kato A (2010) Optimal reconstruction of the bony defect after frontotemporal craniotomy with hydroxyapatite cement. J Clin Neurosci 26:211-218

34. Fernández E, Ginebra MP, Boltong MG, Driessens FC, Ginebra J, De Maeyer EA, Verbeeck RM, Planell JA (1996) Kinetic study of the setting reaction of a calcium phosphate bone cement. J Biomed Mater Res 32:367-374

35. Charrière E, Terrazzoni S, Pittet $\mathrm{C}$, Mordasini $\mathrm{PH}$, Dutoit $\mathrm{M}$, Lemaittre J, Zysset PH (2001) Mechanical characterization of brushite and hydroxyapatite cements. Biomaterials 22:2937-2945

36. Costantino PD, Friedman CD, Jones K, Chow LC, Pelzer HJ, Sisson GA Sr (1991) Hydroxyapatite cement: I. Basic chemistry and histologic properties. Arch Otolaryngol Head Neck Surg 117:379-384

37. Barone CM, Jimenez DF, Boschert MT, Beckert BW (2000) BoneSource solidification: a comparison between water and sodium phosphate as the solvent. J Craniofac Surg 11:495-497

38. Becking AG, Tuinzing DB, Hage JJ, Gooren LJG (1996) Facial corrections in male to female transsexuals: a preliminary report on 16 patients. J Oral Maxillofac Surg 54:413-418

39. Friedman CD, Costantino PD, Jones K, Chow LC, Pelzer HJ, Sisson GA Sr (1991) Hydroxyapatite cement. II. Obliteration and reconstruction of the cat frontal sinus. Arch Otolaryngol Head Neck Surg 117:385-389

40. Taghizadeh F, Krömer A, Laedrach K (2006) Evaluation of hydroxyapatite cement for frontal sinus obliteration after mucocele resection. Arch Facial Plast Surg 8:416-422

41. Ainsworth TA, Spiegel JH (2010) Quality of life of individuals with and without facial feminization surgery or gender-reassignment surgery. Qual Life Res 19(7):1019-1024 